\title{
Epidemiology of alcoholic liver disease in Korea
}

\author{
Jae Young Jang ${ }^{1,3}$, and Dong Joon Kim ${ }^{2,3}$ \\ IInstitute for Digestive Research, Digestive Disease Center, Department of Internal Medicine, Soonchunhyang University College of Medicine, \\ Seoul; ${ }^{2}$ Department of Internal Medicine, Hallym University College of Medicine, Chuncheon, Korea; ${ }^{3}$ Alcohol-Related Problems Study Group, \\ Korea
}

Alcohol consumption has increased over the past 40 years in Korea concomitantly with the country's rapid socioeconomic development. As a result, alcohol-related deaths and mortality continue to increase in Korea. This review will summarize the recent epidemiology of alcoholic liver disease in Korea. (Clin Mol Hepatol 2018;24:93-99)

Keywords: Alcoholic liver disease; Epidemiology; Health policy

\section{INTRODUCTION}

Brewing fermented beverages in China dates back as early as the seventh millennium B.C., and fermented drinks were first mentioned in the founding story of the Goguryeo Kingdom during the reign of King Dongmyeong (B.C. 37-B.C. 19) in the "Poetic Records of Emperors and Kings (Jewangun-gi)". ${ }^{2}$ Drinking "ear-quickening wine (gwibalgisul)" in the hopes of hearing good news at the first full moon of the lunar New Year is one of the long-lasting Korean traditions. Notwithstanding, evidence of drinking alcohol does not necessarily mean the presence of alcoholic liver disease. Due to general food shortages before the modern times, it is assumed that alcoholic beverages were used only in secular or religious ceremonies and drinking for leisure was confined to rulers and upperclass individuals. In the "History of Korean Medicine and of Diseases in Korea", Sakae Miki described that "cirrhosis hepatis (liver cirrhosis) is relatively common but it is difficult to identify the cause." ${ }^{33}$

The hepatitis B antigen (called "Australia antigen" and "hepatitis-associated antigen") was first reported by Bloomberg et al. in
1965. ${ }^{4}$ Thus, attribution of causality or determination of the etiology of chronic liver disease was only possible after the 1970s in Korea. Even in the early 1970s, there were debates on the causality of alcohol in the development of chronic liver disease. ${ }^{5-7}$ In the 1990s, alcoholic liver disease became an important health problem in Korea. ${ }^{8-11}$ This marked change between the 1970s and 1990s was thought to be due to rapid development of the economy and the availability of cheap hard liquor ('soju') after the Grain Management Act in 1965. ${ }^{12}$

Excessive alcohol consumption not only causes a variety of illnesses, including alcoholic liver disease, ${ }^{13}$ but also indirectly causes accidents. Every year, approximately 2.5 million people die from alcohol worldwide, with 320,000 deaths among 15-29 aged people. According to the Organization for Economic Cooperation and Development (OECD) report in 2012, 2.3\% of all deaths in Southeast Asia and more than $5 \%$ in the western Pacific were due to alcohol consumption. ${ }^{14}$

The Korean culture is lenient toward drinking. Alcohol consumption is considered a social activity, and drinking is thought to be an

\section{Abbreviations:}

OECD; Organization for Economic Cooperation and Development

\section{Corresponding author : Dong Joon Kim}

Center for Liver and Digestive Diseases, Hallym University Chuncheon Sacred Heart Hospital, 77 Sakju-ro, Chuncheon 24253, Korea

Tel: +82-33-240-5646, Fax: +82-33-241-8064

Email: djkim@hallym.ac.kr

https://orcid.org/0000-0002-5792-1500 
important component in business and various other social interactions. Alcohol consumption has increased over the past 40 years in Korea concomitantly with the country's rapid socioeconomic development. As a result, alcohol-related deaths and mortality continue to increase in Korea. ${ }^{15}$ Furthermore, the social costs of alcohol (including loss of productivity, health care costs, automobile accidents and crime-related costs) are significant, and these social costs account for approximately $2 \%$ of the GDP in Korea. ${ }^{14}$ According to recent Korean studies based on data from the 2009 KNHANES, approximately $7 \%$ of Korean adults are heavy alcohol consumers (men: $>40 \mathrm{~g} /$ day, women: $>20 \mathrm{~g} /$ day), and approximately $25 \%$ of these heavy alcohol consumers exhibit abnormal liver-function tests. ${ }^{16-18}$ This review will summarize the recent epidemiology of alcoholic liver disease in Korea.

\section{CURRENT STATUS OF ALCOHOL CONSUMPTION AND ALCOHOL USE DISORDERS IN KOREA}

\section{Analysis of Korean alcohol consumption and drinking behavior}

Increasing alcohol consumption in Koreans: consumption of distilled liquor is ranked first in the world

According to the "International Statistical Yearbook 2016" from the National Statistical Office, Korea's annual alcohol consumption per capita in 2014 was 9.0 liters. It ranks 15th among the 188 WHO member countries. ${ }^{19}$ In Korea, distilled liquor, which has an alcohol content that is relatively higher than wine and beer, is the main alcoholic beverage consumed, and $81 \%$ of total alcoholic beverages are distilled liquor. In Korea, where people consume distilled liquor with high alcohol content, it is expected that the influence of alcohol on the occurrence of alcohol-related diseases will be great. The incidence of liver cancer in Korea is twice as high as that of France, which has the third highest alcohol consumption this year, even after accounting for the high prevalence of chronic hepatitis $B$ in Korea. Alcohol consumption in OECD countries has been declining in recent years, but alcohol consumption per capita in Korea is increasing. Domestic alcohol consumption has risen from 13th in 2011 to 11th in 2015. ${ }^{20}$ The total consumption of alcohol in Korea has increased to $14.80 \mathrm{~L}$, with the consumption of distillate at $9.57 \mathrm{~L}$, making it the world's largest.
The highest monthly drinking rates are in people in their $20 \mathrm{~s}$ and $30 \mathrm{~s}$

According to the results of the National Health and Nutrition Survey in 2015, the monthly drinking rates of Korean adults (the standardized proportion of people above the age of 19 years who drink at least once a month) were $74.4 \%$ in males and $43.3 \%$ in females (Fig. 1). ${ }^{21}$ The monthly drinking rates in 2005 were $72.6 \%$ in males and $36.9 \%$ in females and gradually increased from 2005 to 2011 and remained stable in 2015 . The monthly drinking rate by age was the highest in younger age groups; the rate was the highest, at $80.0 \%$, among men in their 30 s, followed by women in their 20 s, at $56.6 \%{ }^{21}$

High-risk drinking habits of Koreans are at a worrisome level According to the National Health and Nutrition Survey in 2015 , high-risk drinking rate (standardized over 19 year olds) was $20.8 \%$ among males and $5.8 \%$ among females. In this survey, the definition of high-risk drinking was defined as consuming alcohol greater than an average of 7 grams ( 5 grams in the case of females) two or more times a week. In men, the high-risk drinking rate was the highest, at 24.5\%, in 2008 and has been decreasing, but for females, there has been a continuous increase since 2005 (Fig. 2). ${ }^{21}$ By age, the highest high-risk drinking rates occur for males in their 30 s and 50 s and for females in their 20s. ${ }^{21}$ According to the WHO, high-risk drinking is defined as $60 \mathrm{~g}$ of alcohol consump-

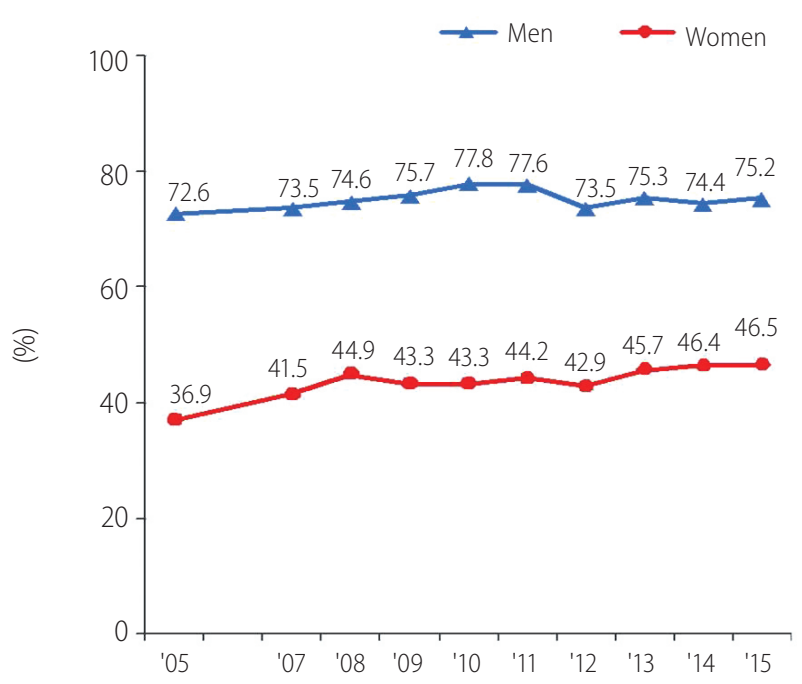

Figure 1. Trend in the monthly drinking rate (Source: National Health and Nutrition Survey, 2016). Monthly drinking rate: Percentage of people who drink more than once a month during the last year, ages 19 and over. Age standardization by the estimated population in 2005. 


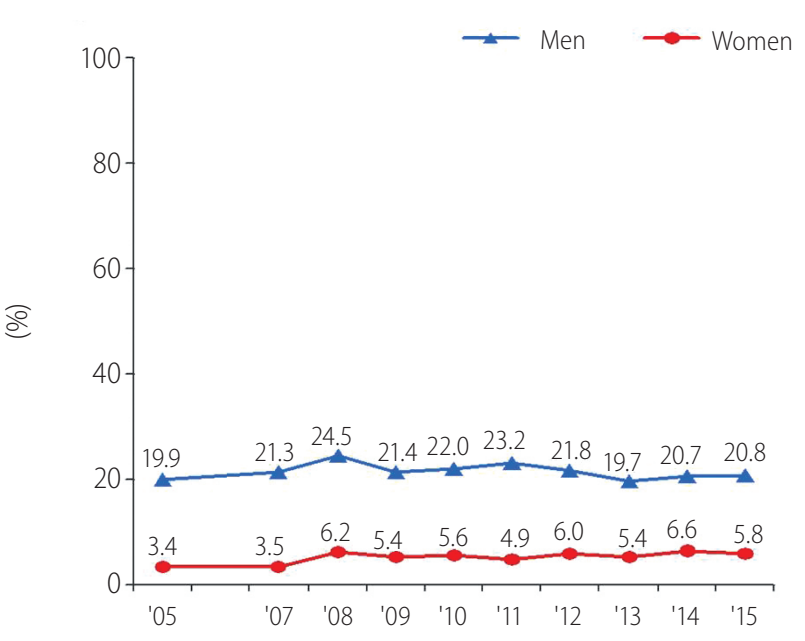

Figure 2. Trend in the high-risk drinking rate (Source: National Health and Nutrition Survey, 2016). High-risk drinking rate The rate of average drinking more than twice a week, 7 grams at a time (women 5 grams). Age standardization by the estimated population in 2005.

tion once or more per week. Compared to the world's average high-risk drinking rates of $16.1 \%$ for males and $4.2 \%$ for females, ${ }^{20}$ the high-risk drinking rate among Koreans is very high.

\section{Status of alcohol use disorders in Korea}

According to the national epidemiologic survey of mental illnesses conducted in Korea in 2016, the lifetime prevalence of alcohol use disorders among the 5,000 general adult population between 18 and 74 years old living in the community is the highest among all psychiatric disorders, $12.2 \% .^{22}$ In particular, the lifetime prevalence among males was $18.1 \%$, with one in five men experiencing alcohol abuse during their lifetime.

The prevalence of alcohol use disorders in 2016 shows a steady decline compared to that of the 2001, 2006 and 2011 surveys, particularly in alcohol dependence compared to alcohol abuse. However, the prevalence of alcohol use disorders in women has not decreased significantly, and there has been an increase trend in alcohol abuse cases. Therefore, it is necessary to pay attention to the increasing alcohol problem in women.

Although the prevalence of alcohol use disorders in the Korean population is decreasing, it remains high compared to other countries. Given that the prevalence of alcohol use disorder is less than $10 \%$ in European men according to data from the WHO, the problem of alcohol use disorders in Korea is very serious. In addition, the rate of people with alcohol use disorders seeking mental health services is very low compared to those with other psychiatric disor- ders. It is necessary to recognize and focus on alcohol use disorders as a serious issue for our society.

\section{NATURAL HISTORY AND BURDEN OF ALCO- HOLIC LIVER DISEASE}

\section{Natural history of alcoholic liver disease}

Alcoholic fatty liver is the most common disease that can occur in people who drink alcohol, but in this stage, recovery to the normal liver is possible if alcohol is withdrawn. However, when alcoholic hepatitis occurs, progression to hepatic fibrosis is common, and if alcoholic hepatitis persists over a long period, the progression of liver fibrosis accelerates, leading to cirrhosis. More than half of the patients with alcoholic cirrhosis have complications at the time of diagnosis, ${ }^{23}$ and the incidence of liver cancer and the risk of death are high with alcoholic cirrhosis. ${ }^{24,25}$

Alcoholic fatty liver occurs in over $90 \%$ of those who consume $60 \mathrm{~g}$ or more of alcohol per day, but alcoholic hepatitis accompanied by hepatic inflammation is observed only in one-third of chronic drinkers. ${ }^{26}$ Alcoholic fatty liver is usually asymptomatic, and it can be completely alleviated by 4 to 6 weeks of abstinence. ${ }^{27}$ However, when the alcohol use continues, hepatic fibrosis and cirrhosis occur in 20 to $40 \%$ and 8 to $20 \%$ of long-term drinkers, respectively. Fatty liver is generally thought to be a reversible change, but it can proceed to liver cirrhosis from fatty liver despite abstinence. ${ }^{28}$

The risk of liver cancer in patients with cirrhosis is approximately $1.5 \%$ per year, and 3 to $10 \%$ of chronic alcohol users develop cirrhosis, eventually causing liver cancer. ${ }^{29}$ In the study of the National Danish Registry, the rate of progression of alcoholic hepatitis to cirrhosis after 5 years was $16 \%$, which is higher than that (6.9\%) of patients with simple fatty liver disease. ${ }^{30}$ The rate at which alcoholic hepatitis progresses to alcoholic cirrhosis is approximately 10 to $20 \%$ per year, and finally, $70 \%$ of alcoholic hepatitis will progress to liver cirrhosis. ${ }^{25}$

\section{Burden of alcoholic liver disease}

Alcoholic liver disease is the most important cause of death among alcohol-related diseases

According to the 2016 National Statistical Office's "Cause of Death Statistics for 2015", the number of deaths due to alcoholrelated illnesses increased by $5.8 \%$ year-over-year to 4,746 , with 
a mortality rate of 9.3 per 100,000 . In particular, 3,748 (82.4\%) deaths from alcoholic liver disease were detected in 3,355 men and 393 women, suggesting that alcoholic liver disease is the most important cause of alcohol-related death. Male death rates were 6.8 times higher than those of females, and increase of alcohol-related deaths was started at the age of 40 and peaked in the 50s. ${ }^{31}$ From 1989 to 2006, two Korean university hospitals investigated mortality in 442 patients with alcohol dependence who were discharged from those hospitals. In December 2009, 127 people $(29 \%)$ had died. ${ }^{32}$ The mortality rate was 6.7 times higher than that of the general sex- and age-matched population; the mean age of the patients was 48.8 years. By sex, the mortality rate was 7.1 times higher in men and 2.6 times higher in women than the general population. The most common cause of death was alcoholic liver disease. In particular, patients admitted to the hospital several times for alcohol dependence with low blood albumin or high bilirubin levels had a significantly higher mortality rate. $^{32}$

\section{Rapid increase in insurance claims related to alcoholic} liver disease

Estimating the social costs of alcoholic liver disease is difficult because many patients with alcoholic liver disease are excluded from society and even from their own families. These patients do not receive the proper treatment for liver disease or rehabilitation to achieve abstinence. It is difficult to determine the exact burden of alcoholic liver disease on medical or non-medical costs. According to a 2009 survey by the Korea Institute for Health and Social Affairs, the social cost of smoking is 5,639.6 billion won a year, while the social cost of drinking is 18.9 trillion won, three time greater than that of smoking. ${ }^{33}$ According to the data of the recent Health Insurance Review Assessment Institute, the number of claims for alcoholic liver disease (K70) declined (-12.3\%) from 2012 to 2016 (approximately 147,000 in 2012 to 129,000 in 2016); however, total medical expenses increased by approximately 18.4 billion won (approximately 27.4\%) over the five years from 61 billion won in 2012 to 85 billion won in 2016. The number of patients with alcoholic disease has decreased in 3 years, but the cost of medical care has been rising. ${ }^{34}$

Alcoholic liver disease is more common in middle-aged men in their 40s and 50s who are socially and economically active. This is mainly attributed to the fact that men who work have a greater number of drinks compared to women. ${ }^{34}$ Thus, the socioeconomic burden of alcoholic liver disease in socially functioning middle-aged men is significant.

\section{CURRENT SATATUS OF ALCOHOLIC LIVER DIS- EASE IN KOREA}

\section{Outline of alcoholic liver disease}

\section{Alcohol is a major cause of liver disease}

Alcohol is one of the most common causes of liver disease along with viral hepatitis. Although there are no national statistics to date, alcoholic liver disease is estimated to account for $13-14.5 \%$ of the total number of liver diseases in Korea. ${ }^{11,35}$

Alcoholic liver disease is historically classified into the following three types: alcoholic fatty liver disease, alcoholic hepatitis, and alcoholic cirrhosis. Alcoholic fatty liver disease is a condition in which the liver is infiltrated by fat, while alcoholic hepatitis is a condition in which fatty liver is persistent, accompanied by inflammation and necrosis of the hepatocytes. ${ }^{35}$ In alcoholic cirrhosis, severe fibrosis and regeneration nodule are formed and the surface of the liver becomes rough.

\section{Risk factors of alcoholic liver disease}

Alcohol plays the most important role in the mechanism of alcoholic liver disease development. However, alcoholic liver disease does not occur in everyone who consumes alcohol. In other words, genetic factors (genetic polymorphism of alcohol metabolizing enzymes and genetic susceptibility of alcoholic liver damage) and environmental factors (gender, nutritional status, accompanying liver disease, etc.) are involved in the development of alcoholic liver disease. ${ }^{36} \mathrm{It}$ is not fully understood how these factors affect the occurrence and progression of alcoholic liver disease. The minimum intake of alcohol that causes alcoholic liver disease is approximately 40 to 80 grams per day for at least one year but can occur at lower doses in women or people with chronic hepatitis C. ${ }^{37-39}$ Although there is no absolute criteria of the amount of alcohol that causes alcoholic liver disease, the KASL Alcoholic Liver Disease Clinical Practice Guidelines suggest that a daily average alcohol intake exceeding $40 \mathrm{~g}$ for men and $20 \mathrm{~g}$ for women is a criterion to diagnose alcoholic liver disease. ${ }^{18}$

\section{Alcohol also causes various diseases other than liver disease}

In addition to liver disease, diseases caused by excessive alcohol consumption include dementia, encephalopathy, dilated cardiomyopathy, pancreatitis and fetal malformation. 


\section{Current status of alcoholic liver disease in Korea}

\section{A total of 129,279 people has been diagnosed with} alcoholic liver disease

According to the National Health Insurance Corporation, the total number of patients treated for alcoholic liver disease in 2016 was 129,279 , of whom $111,283(86.5 \%)$ were male and 17,996 $(13.5 \%)$ were female (Table 1). ${ }^{40}$ In men, according to age, prevalence of alcoholic liver disease was the highest among those in their 50s $(37,640)$, followed by the 60s $(25,931)$ and $40 \mathrm{~s}(24,517)$. In women, the prevalence was the highest among those in their
50 s $(5,520)$, followed by the 40 s $(4,903)$ and 30 s $(2,936)$. According to the 2013 data from the National Health Insurance Corporation, detailed information of the patients showed the following breakdown of alcoholic liver diseases in men: alcoholic fatty liver $(38,705,30.4 \%)$, alcoholic hepatitis (31,956, 25.1\%), and alcoholic cirrhosis $(19,159,15.0 \%)$. This distribution was similar for women. With increasing age, the proportion of alcoholic fatty liver decreased and the proportion of alcoholic cirrhosis increased. ${ }^{41}$ (Table 1)

Table 1. Number of patients treated for alcoholic liver disease (National Health Insurance Corporation, Korea)

\begin{tabular}{|c|c|c|c|c|c|c|c|}
\hline Division & & 2010 & 2011 & 2012 & 2013 & 2014 & 2015 \\
\hline \multirow[t]{3}{*}{ Total } & Total & 149,521 & 147,845 & 145,019 & 136,362 & 129,670 & 127,242 \\
\hline & Men & 129,319 & 127,930 & 124,205 & 117,049 & 112,251 & 110,012 \\
\hline & Women & 20,202 & 19,915 & 20,814 & 19,313 & 17,419 & 17,230 \\
\hline \multirow[t]{3}{*}{ Under 19} & Total & 631 & 484 & 551 & 431 & 324 & 332 \\
\hline & Men & 485 & 363 & 375 & 310 & 236 & 247 \\
\hline & Women & 146 & 121 & 176 & 121 & 88 & 85 \\
\hline \multirow[t]{3}{*}{ The 20s } & Total & 7,006 & 6,152 & 5,327 & 4,390 & 3,944 & 3,699 \\
\hline & Men & 5,174 & 4,529 & 3,835 & 3,256 & 2,991 & 2,828 \\
\hline & Women & 1,832 & 1,623 & 1,492 & 1,134 & 953 & 871 \\
\hline \multirow[t]{3}{*}{ The 30s } & Total & 20,552 & 19,411 & 17,670 & 15,428 & 14,047 & 12,992 \\
\hline & Men & 16,810 & 15,814 & 14,106 & 12,206 & 11,193 & 10,224 \\
\hline & Women & 3,742 & 3,597 & 3,564 & 3,222 & 2,854 & 2,768 \\
\hline \multirow[t]{3}{*}{ The 40s } & Total & 38,382 & 36,494 & 34,628 & 32,111 & 29,977 & 28,313 \\
\hline & Men & 33,191 & 31,331 & 29,555 & 27,240 & 25,462 & 23,825 \\
\hline & Women & 5,191 & 5,163 & 5,073 & 4,871 & 4,515 & 4,488 \\
\hline \multirow[t]{3}{*}{ The 50s } & Total & 45,501 & 47,354 & 47,219 & 45,325 & 43,405 & 42,012 \\
\hline & Men & 40,029 & 41,693 & 41,262 & 39,598 & 38,028 & 36,687 \\
\hline & Women & 5,472 & 5,661 & 5,957 & 5,727 & 5,377 & 5,325 \\
\hline \multirow[t]{3}{*}{ The $60 \mathrm{~s}$} & Total & 25,775 & 25,619 & 26,366 & 25,559 & 25,360 & 27,018 \\
\hline & Men & 23,356 & 23,276 & 23,616 & 23,002 & 23,119 & 24,648 \\
\hline & Women & 2,419 & 2,343 & 2,750 & 2,557 & 2,241 & 2,370 \\
\hline \multirow[t]{3}{*}{ The 70 s } & Total & 10,502 & 10,976 & 11,785 & 11,602 & 11,042 & 11,082 \\
\hline & Men & 9,338 & 9,823 & 10,317 & 10,221 & 9,939 & 10,055 \\
\hline & Women & 1,164 & 1,153 & 1,468 & 1,381 & 1,103 & 1,027 \\
\hline \multirow[t]{3}{*}{ Over the $80 \mathrm{~s}$} & Total & 1,172 & 1,355 & 1,473 & 1,516 & 1,571 & 1,794 \\
\hline & Men & 936 & 1,101 & 1,139 & 1,216 & 1,283 & 1,498 \\
\hline & Women & 236 & 254 & 334 & 300 & 288 & 296 \\
\hline
\end{tabular}

Based on actual date of treatment, classification of oriental medicine and pharmacy excluded. 2015 will be reflected until June 2016 payment, there may be uncharged data. It may be different from the final confirmed disease because it is extracted from the primary diagnosis according to clinical diagnosis by physician where the diagnosis is not confirmed during treatment in the medical care institution. 


\section{The proportion of alcoholic liver disease among chronic liver diseases in Korea}

In Korea, alcohol is the second most common cause of hepatitis B virus infection is $64.9 \%$ of cirrhosis and alcohol is $18.6 \%$ alcohol at $18.6 \% .{ }^{9.42}$ Furthermore, alcohol is the 3rd most common cause of liver cancer (hepatitis B, 72\%; hepatitis C, 12.5\%; alcohol, 6.8\%). However, considering that frequent alcohol use increases the incidence of liver cirrhosis and hepatocellular carcinoma in viral hepatitis patients, the influence of alcohol use on the incidence of liver cirrhosis and liver cancer has clinically significance greater than the aforementioned values.

\section{CONCLUSIONS}

The per-capita alcohol consumption in Korea is now considered to be among the highest in the world. Economic loss due to alcohol-related diseases and accidents has increased with the increase in alcohol consumption. ${ }^{18}$ According to the WHO report, Korea is rated as a country where the alcohol burden is high but a national plan for alcohol has not been implemented. ${ }^{20}$

To drastically lower alcohol-related diseases and the socioeconomic burden of alcohol in Korea, the establishment of basic law such as Japan's "Basic Law on Measures Against Health Problems Caused by Alcohol Intake (Act No. 109 of 2013)" should be prioritized. ${ }^{43,44}$ Enactment of a law that obligates the national and local governments to establish measures to reduce alcohol-related problems can appropriately improve the alcohol-related policy in Korea.

\section{Conflicts of Interest}

The authors have no conflicts to disclose.

\section{REFERENCES}

1. McGovern PE, Zhang J, Tang J, Zhang Z, Hall GR, Moreau RA, et al. Fermented beverages of pre- and proto-historic China. Proc Natl Acad Sci U S A 2004;101:17593-17598.

2. Korea Tourism Organization, Korean Culture and Information Service (KOCIS). Makgeolli the rice wine-Say hello to the latest Korean fervor. Imagine your Korea web site <http://english.visitkorea.or.kr/enu/AKR/ FU_EN_15.jsp?cid=806261>. Accessed 2017.11.25.

3. Sakae Miki. History of Korean Medicine and of Diseases in Korea. Osaka: Fuji Seihan Printing, 1963.

4. Blumberg BS, Alter HJ, Visnich S. A "new" antigen in leukemia sera.
JAMA 1965;191:541-546.

5. Kim CY. Liver cirrhosis in Korean: Introduction. Korean J Med 1974; 17:541-543.

6. Choi HJ. Pathogenesis of liver cirrhosis. Korean J Med 1974;17:544551.

7. Yu G, Lee PW, Kim CY. Alcoholic hepatitis-report of a case. Korean J Med 1975;18:65-72.

8. Kim ND, Kwon SO, Kim HS, Lee DK, Bae SW, Jang WI, et al. Clinical study of alcoholic liver disease. Korean J Med 1992;43:161-168.

9. Seo KS, Lee BS, Sung JK, Lee SO, Kim SH, Kim KT, et al. The cause and complication of liver cirrhosis during recent 5 years. Korean J Hepatol 1997;3:202-209.

10. Han YS, Kim BH, Baek IY, Lee DK, Kim KJ, Dong SH, et al. The change of the etiology, complications and cause of death of the liver cirrhosis in 1990s. Korean J Hepatol 2000;6:328-339.

11. Lee SS, Byoun YS, Jeong SH, Kim YM, Gil H, Kim BY, et al. Type and cause of liver disease in Korea: single-center experience, 2005-2010. Clin Mol Hepatol 2012;18:309-315.

12. Korean Legislation Research Institute. Contents of statutes of the Republic of Korea. Grain Management Act. KLRI Website <https://klri. re.kr/eng/category/publicationTwo.do>. Accessed 2017.11.25.

13. Shah VH. Managing alcoholic liver disease. Clin Mol Hepatol 2015;21: 212-219.

14. The Organisation for Economic Co-operation and Development, World Health Organization. Health at a Glance: Asia/Pacific 2012. OECD iLibrary web site <http://www.oecd-ilibrary.org/social-issues-migration-health/health-at-a-glance-asia-pacific-2012_9789264183902en>. Accessed 2017.11.25.

15. Ministry of Health and Welfare. The Third National Health Promotion Comprehensive Plan (2011-2020). 2011.

16. Park SH. Association between alcohol consumption and metabolic syndrome among Korean adults: nondrinker versus lifetime abstainer as a reference group. Subst Use Misuse 2012;47:442-449.

17. Park SH, Kim CH, Kim DJ, Park JH, Kim TO, Yang SY, et al. Prevalence of alcoholic liver disease among Korean adults: results from the fourth Korea National Health and Nutrition Examination Survey, 2009. Subst Use Misuse 2011;46:1755-1762.

18. Korean Association for the Study of the Liver (KASL).KASL clinical practice guidelines: management of alcoholic liver disease. Clin Mol Hepatol 2013;19:216-254.

19. Statistical Office. International Statistical Yearbook 2016. 2016.

20. World Health Organization. Global status report on alcohol and health 2014. WHO web site <http://www.who.int/substance_abuse/publications/global_alcohol_report/en/>. Accessed 2017.11.25.

21. Ministry of Health and Welfare, Disease Control Headquarters. 2015 National Health Statistics National Health and Nutrition Examination Sixth Third year (2015). 2016.

22. Ministry of Health and Welfare. 2016 Mental Illness Epidemiology Sur- 
vey. 2017.

23. Jepsen P, Ott P, Andersen PK, Sørensen HT, Vilstrup H. Clinical course of alcoholic liver cirrhosis: a Danish population-based cohort study. Hepatology 2010;51:1675-1682.

24. Horie Y, Yamagishi Y, Kajihara M, Kato S, Ishii H. National survey of hepatocellular carcinoma in heavy drinkers in Japan. Alcohol Clin Exp Res 2003;27(8 Suppl):32S-36S.

25. Fleming KM, Aithal GP, Card TR, West J. All-cause mortality in people with cirrhosis compared with the general population: a populationbased cohort study. Liver Int 2012;32:79-84.

26. Barrio E, Tomé S, Rodríguez I, Gude F, Sánchez-Leira J, Pérez-Becerra $E$, et al. Liver disease in heavy drinkers with and without alcohol withdrawal syndrome. Alcohol Clin Exp Res 2004;28:131-136.

27. Crabb DW. Pathogenesis of alcoholic liver disease: newer mechanisms of injury. Keio J Med 1999;48:184-188.

28. Sørensen TI, Orholm M, Bentsen KD, Høybye G, Eghøje K, Christoffersen $P$. Prospective evaluation of alcohol abuse and alcoholic liver injury in men as predictors of development of cirrhosis. Lancet 1984; 2:241-244.

29. Schwartz JM, Reinus JF. Prevalence and natural history of alcoholic liver disease. Clin Liver Dis 2012;16:659-666.

30. Deleuran T, Grønbaek H, Vilstrup H, Jepsen P. Cirrhosis and mortality risks of biopsy verified alcoholic pure steatosis and steatohepatitis: a nationwide registry-based study. Aliment Pharmacol Ther 2012:35:1336-1342.

31. Statistical Office. Cause of death in 2015. 2016.

32. Park S, Hong JP, Choi SH, Ahn MH. Clinical and laboratory predictors of all causes deaths and alcohol-attributable deaths among discharged alcohol-dependent patients. Alcohol Clin Exp Res 2013;37:270-275.

33. Jeong YH, Choi EJ, Ko SJ, Kim EJ, Choi MC. Cost - effectiveness analysis of socioeconomic costs and alcohol abuse prevention. Korea Institute for Health and Social Affairs, Korea Health Promotion Foundation 2012

34. Health Insurance Review and Assessment Service. Disease statistics by hospitalization and outpatient. Healthcare Big Data Opening
System Web site <http://opendata.hira.or.kr/op/opc/olap3thDsInfo. do>. Accessed 2017.11.25.

35. Kwon SO. Clinical Significance of Alcoholic Liver Disease and Domestic Status. In: Lee CH, ed. The Korean Journal of Gastroenterology. 2nd ed. Seoul: Gunja Publishing Co., 2005: 219-231.

36. Becker U, Deis A, Sørensen TI, Grønbaek M, Borch-Johnsen K, Müller $C F$, et al. Prediction of risk of liver disease by alcohol intake, sex, and age; a prospective population study. Hepatology 1996;23:1925-1029.

37. Kim NY, Kim A, Im SH, Kim SY, Yong SY, Lee GH, et al. A Study on the Correlation between HCV Antibody Positivity and Liver Damage in Korean Drinkers. Korean J Int Med 1993;44:666-673.

38. Brick J. Standardization of alcohol calculations in research. Alcohol Clin Exp Res 2006;30:1276-1287.

39. Savolainen VT, Liesto K, Mannikko A, Penttila A, Karhunen PJ. Alcohol consumption and alcoholic liver disease: evidence of a threshold level of effects of ethanol. Alcohol Clin Exp Res 1993;17:1112-1117.

40. National Health Insurance Corporation. Drinking influences Alcoholic epilepsy patients account for $64.4 \%$ over 50 s. NHIC website $<$ http://www.nhis.or.kr/menu/retriveMenuSet.xx?menuld=D4000>. Accessed 2016

41. National Health Insurance Corporation. Among the $50 \%$ of middleaged men with alcoholic liver disease, $28.2 \%$ were the most. NHIC website $<$ http://www.nhis.or.kr/menu/retriveMenuSet.xx?menuld=D4000>. Accessed 2013.

42. Kim DJ, Suk KT, Park SH. Epidemiologic changes of alcoholic liver disease. Korean J Hepatol. 2011;17(Suppl 3):S169-S176.

43. Umeda S. Japan: Basic Law on Measures Against Health Problems Caused by Alcohol Intake. The Library of Congress: Law Library Website <http://www.loc.gov/law/foreign-news/article/japan-basiclaw-on-measures-against-health-problems-caused-by-alcoholintake/>. Accessed 2017.11.25.

44. Basic Law on Measures Against Health Problems Caused by Alcohol Intake <http://law.e-gov.go.jp/announce/H25H0109.html>. Accessed 2017.04.30. 